\title{
Toluene-Induced Locomotor Activity is Blocked by 6- Hydroxydopamine Lesions of the Nucleus Accumbens and the mGluR2/3 Agonist LY379268
}

\author{
AC Riegel ${ }^{1,3}$, SF Ali $^{2}$, ED French*,1 \\ 'Department of Pharmacology, College of Medicine, University of Arizona, Tucson, AZ, USA; ${ }^{2}$ Neurochemistry Laboratory, Division of \\ Neurotoxicology, National Center for Toxicological Research/US FDA, Jefferson, AR, USA
}

\begin{abstract}
The abuse of volatile inhalants remains a prominent, yet poorly understood, form of substance abuse among youth. Nevertheless, the identification of a mechanism underlying the reinforcing properties of inhalants has been hampered by the lack of a clearly identifiable neural substrate upon which these chemicals act. One ingredient that is common to many abused inhalants is toluene, an organic solvent that is self-administered by nonhuman primates and rodents. Most drugs of abuse have been found to elicit forward locomotion in rats, an effect owing to the activation of mesoaccumbal dopamine (DA) pathways. Thus, the present study was undertaken using two different approaches to determine whether toluene-induced locomotor hyperactivity is also ultimately dependent upon DA neurotransmission in the mesolimbic nucleus accumbens (NAC). Here we report on the effects of 6-hydroxydopamine (6-OHDA) lesions of the NAC or pretreatment with the metabotropic mGlu2/3 receptor agonist LY379268 on toluene-induced locomotor activity. Both procedures, which are known to alter neurotransmission within the NAC, significantly attenuated toluene's locomotor stimulatory effects. These results provide strong support for a central mechanism of action of inhalants, which in the past has been more typically attributed to general nonspecific mechanisms throughout the brain. Moreover, as with other drugs of abuse, the NAC may be the final common pathway subserving toluene's abuse liability.

Neuropsychopharmacology (2003) 28, 1440-1447, advance online publication, 7 May 2003; doi:10.1038/sj.npp. 1300193
\end{abstract}

Keywords: 6-hydroxydopamine; inhalant abuse; toluene; nucleus accumbens; dopamine; metabotropic glutamate receptors

\section{INTRODUCTION}

The incidence of inhalant abuse is exceeded at present only by alcohol, cigarette and marijuana use (NIDA Research Report, 1999). As with other drugs of abuse, inhalants can produce a variety of symptoms including euphoria, hallucinations, dependence, and psychosis (Flanagan and Ives, 1994; Balster, 1998). In fact, inhalants produce in humans a level for pleasant feelings equivalent to that produced by methamphetamine but more than that produced by either alcohol or nicotine (Kono et al, 2001). Toluene, a prototypical solvent found in many substances inhaled for their psychotropic effects, has also been shown

* Correspondence: Dr E French, Department of Pharmacology, University of Arizona, College of Medicine, Tucson, AZ 85724-5050, USA, Fax: + I 520 626-2204, E-mail: efrench@u.arizona.edu

${ }^{3}$ Current address: Cellular Neurobiology Branch, Section on Neurophysiology, National Institute on Drug Abuse, National Institutes of Health, US Department of Health and Human Services, Baltimore, MD 21224, USA.

Received 25 October 2002; revised 21 February 2003; accepted 25 February 2003

Online publication: 12 March 2003 at http://www.acnp.org/citations/ Npp03 120339|/default.pdf to support self-administration in monkeys (Weiss et al, 1979), produce a conditioned place preference in mice (Funada et al, 2002), and to enhance intracranial selfstimulation (ICSS) at lower concentrations in the rat (Yavich and Zvartau, 1994). These positive findings in animals confirm the observation that toluene-containing inhalants possess abuse liability in humans.

A common property of drugs of abuse is to increase dopaminergic neurotransmission in mesolimbic terminal regions, such as the nucleus accumbens (NAC) (DiChiara and Imperato, 1988; Koob, 1992). This effect is thought to underlie not only the locomotor stimulatory effects of these substances, but to play a pivotal role in the reinforcing and abuse liability properties of drugs of abuse. In fact, the correlation between increased extracellular levels of dopamine (DA) in the NAC, and the reinforcing/locomotor stimulant effects of such drugs as nicotine, cocaine, amphetamine, and PCP has been well established through the use of 6-hydroxydopamine (6-OHDA) lesions of the NAC. Although the cellular site(s) and mechanism(s) mediating the central actions of abused inhalants containing toluene have not been completely identified, there is substantial neurobehavioral and electrophysiological data to support a toluene-DA interaction (von Euler, 1994). For 
example, toluene both in vivo and in vitro increases rat ventral tegmental DA neuronal excitability (Riegel and French, 1999a; French and Riegel, 2001). Futhermore, the administration of toluene to freely behaving animals produces increased levels of extracellular DA in the striatum (Stengard et al, 1994). If toluene-induced locomotor activity is also mediated through increased mesolimbic dopaminergic neurotransmission, then it is reasonable to expect that 6OHDA lesions of the NAC would abolish this effect.

The recent identification of selective ligands for metabotropic glutamate receptor (mGluRs) subtypes also provides an alternative opportunity to test for a toluene-DA interaction. In contrast to neurochemical lesions, this pharmacological approach relies upon the activation of mGlu receptors localized to presynaptic terminals in the NAC. When stimulated under high agonist availability mGlu $2 / 3$ receptors mediate a negative feedback onto neuronal signaling (Ohishi et al, 1994; Shigemoto et al, 1997). mGlu2/3 receptors are densely expressed in the NAC, and when stimulated regulate both glutamatergic and nonglutamatergic (ie GABA, DA, serotonin)-mediated neurotransmission (Testa et al, 1994; Cartmell and Schoepp, 2000; Schoepp, 2001). For example, pretreatment with LY379268, a nanomolar potent and systemically active mGlu2/3-receptor agonist possessing 10000 -fold selectivity over other mGluRs, attenuated the DA-dependent hyperactivity evoked by amphetamine and PCP (Moghaddam and Adams, 1998; Cartmell et al, 2000a; Clark et al, 2002). Since LY379268 may be a unique pharmacological agent for disrupting neurotransmission in the NAC, we examined the effects of this selective mGluR2/3 agonist on the locomotor stimulant effects of toluene.

Given both the obvious popularity and potential detrimental effects attributed to inhalants, the identification of the neuronal substrate underlying the abuse potential of these compounds remains a critical step in understanding how these classes of drugs influence brain function. Here we focus on identifying a neural substrate mediating one of the behavioral effects of the abused inhalant toluene. The studies described herein employ a well-established neurobehavioral correlate for enhanced mesolimbic neurotransmission, namely locomotor activity (Koob, 1992). Based on their clearly recognized ability to precipitate DA-dependent and -independent locomotor activity, amphetamine and scopolamine were selected to serve as positive and negative controls, respectively (Joyce and Koob, 1981; Riegel and French, 1999c). To moderate a potential interference from other biogenic amines and further confer a degree of selectivity for DA, test subjects also received pretreatments of the noradrenergic blocker desipramine, whose relative binding affinities are described elsewhere (Frazer, 2001). The results of this study specifiy a central mechanism of action for a commonly abused solvent, which appears ultimately to be dependent upon DA neurotransmission in the NAC.

\section{MATERIALS AND METHODS}

All experiments were conducted on 240-300 g male Sprague-Dawley rats (Harlan Sprague Dawley, Inc.) according to protocols approved by the University of Arizona
Institutional Animal Care and Use Committee. In all instances, the animals were maintained in a central animal facility under controlled lighting ( $12 \mathrm{~h}$ light/dark schedule) and temperature, with free access to food and water. All animals were pharmacologically naive and were randomly assigned to the various experimental groups. For several days prior to any drug treatment all rats were acclimated to the activity cages for a total of $5 \mathrm{~h}$. On the day of drug challenge each rat was again exposed to the cage for $60 \mathrm{~min}$ immediately preceding drug injection. Following injection, no entry into the testing room occurred until the 3-h evaluation period was complete. Gross behavioral observations were made but not quantified. Statistical comparisons of the grouped data were made using Student's $t$-test, while drug treatment interactions were analyzed by one-way analysis of variance followed by Dunnett's multiple comparison test. A $P$ value of $<0.05$ was considered statistically significant. Data are presented as the mean \pm standard error of the mean (SEM).

\section{6-OHDA Experiments}

The surgical preparation and neuroanatomical coordinates used to inject rats with 6-OHDA or vehicle into the NAC are described in detail elsewhere (French and Vantini, 1984). To confer a degree of selectivity for the uptake of 6-OHDA into DA terminals and to minimize monoamine oxidase (MAO)mediated degradation of the neurotoxin each animal was pretreated with pargyline $(50 \mathrm{mg} / \mathrm{kg}$, i.p.) and desipramine (25 mg/kg, i.p.) (Sigma Chemicals, St Louis, MO, USA) $30 \mathrm{~min}$ prior to bilateral 6-OHDA injections $(4 \mu \mathrm{g} / \mu \mathrm{l}$ free base in a vehicle solution containing $0.2 \mathrm{mg} / \mathrm{ml}$ ascorbic acid in $165 \mathrm{mM} \mathrm{NaCl}$ ) (Frazer 2001; French and Vantini, 1984). Animals comprising the sham group were treated in an identical manner but received bilateral NAC injections of the vehicle solution. A 30-gauge stainless-steel cannula was used to inject $2 \mu \mathrm{l}$ of $6-\mathrm{OHDA}$ or vehicle at a rate of $1 \mu \mathrm{l} /$ $3 \mathrm{~min}$. At the end of the infusion the cannula remained in place for an additional $3 \mathrm{~min}$. Locomotor activity measurements were begun 14 days following surgery. Horizontal activity was measured in photocell-equipped cages as previously described (Riegel and French, 1999c). Photocell beam interruptions were recorded every $10 \mathrm{~min}$ for a total of $3 \mathrm{~h}$. A more thorough analysis of the dose-response relation for toluene has been previously published by our laboratory (Riegel and French, 1999c). Based on these earlier studies, the dose of toluene used here $(600 \mathrm{mg} / \mathrm{kg}$, i.p.) was selected for its ability to produce adequate locomotor stimulation in the absence of an interfering ataxia that begins to be expressed at higher doses.

In the saline and 6-OHDA-injected animals, systemic challenges with amphetamine, scopolamine, toluene, and an olive oil vehicle were given every other day. Specifically, three treatment groups were tested (naive, 6-OHDA lesioned and sham lesioned; $n=8$ /group). Animals from the three groups received amphetamine $(1.5 \mathrm{mg} / \mathrm{kg}$, i.p.) on day 15 , toluene $(600 \mathrm{mg} / \mathrm{kg}$, i.p.) on day 17 , scopolamine $(1.25 \mathrm{mg} / \mathrm{kg}$, i.p.) on day 19 , and olive oil vehicle $(1.5 \mathrm{ml}$, i.p.) on day 20 postsurgery.

At $24 \mathrm{~h}$ after the last drug challenge, the animals were sacrificed (day 21) and the NAC was removed bilaterally and stored frozen at $-80^{\circ} \mathrm{C}$ until the later determination of 
DA content using HPLC techniques as described elsewhere (Imam and Ali, 2001).

\section{LY379268 Experiments}

Single daily i.p. injections of $1.5,3$, or $6 \mathrm{mg} / \mathrm{kg}$ of the mGluR2/3 agonist LY379268 were made over the course of 8 , 9, and 12 days, respectively, in order to initiate a tolerance to the motor-depressant effects associated with LY379268 as described elsewhere (Cartmell et al, 2000b). The number of vehicle injections given to the control animals was matched to the same number of injections that were given to the $6 \mathrm{mg} / \mathrm{kg}$ LY379268 group. On days 9, 10, and 13, each group of animals again received $1.5,3$, or $6 \mathrm{mg} /$ $\mathrm{kg}$ of LY379268, respectively, and $30 \mathrm{~min}$ later they were challenged with toluene $(600 \mathrm{mg} / \mathrm{kg}$, i.p.).

\section{Drugs}

The doses of the challenge drugs were selected for their demonstrated optimal effects on forward locomotion (French and Vantini, 1984; Riegel and French, 1999c). Toluene (99.8\% purity) and its olive oil vehicle solution were prepared as described elsewhere (Riegel and French, 1999c). The final volume for all toluene injections was $1.5 \mathrm{ml}$. Dextro-amphetamine sulfate (Smith Kline and French Labs, Philadelphia, USA) and scopolamine $\mathrm{HCl}$ (Research Biochemicals International, MA, USA) were dissolved in saline, and their doses were calculated based upon weight of the salt. LY379268, which was kindly provided by Lilly Research Laboratories, Eli Lilly Company, was dissolved in water.

\section{RESULTS}

\section{6-OHDA Experiments}

Previously published studies demonstrate that the DAdependent pattern of locomotor activity associated with injections of amphetamine is highly sensitive to 6-OHDA lesions of the NAC. In contrast, the pattern of locomotor activity produced by scopolamine has also been extensively examined, but it appears unrelated to DA neurotransmission and thus insensitive to 6-OHDA lesions (Joyce and Koob, 1981; French and Vantini, 1984). On this basis, the test compounds amphetamine and scopolamine served as positive and negative controls, respectively. The locomotor stimulatory effects of toluene, amphetamine, scopolamine, and vehicle over the 180 min following injection are shown in Figures 1 and 2. The locomotor activity produced in response to injections of toluene in the present study was comparable to that seen in a previously published study (Riegel and French, 1999c). When compared to vehicle, injections of amphetamine, toluene, and scopolamine produced significant increases in activity (compare inset graphs of Figure $2 b$ with Figures $1 \mathrm{a}$ and b, 2a). Although the amount of locomotor activity produced by amphetamine is clearly greater than that produced by toluene, the effects of both agents were significantly reduced in the 6-OHDAlesioned animals compared to the sham-lesioned group (amphetamine by $66.5 \%, P<0.01$, and toluene by $55 \%$, $P<0.02)$. The responses of the naive and sham-lesioned
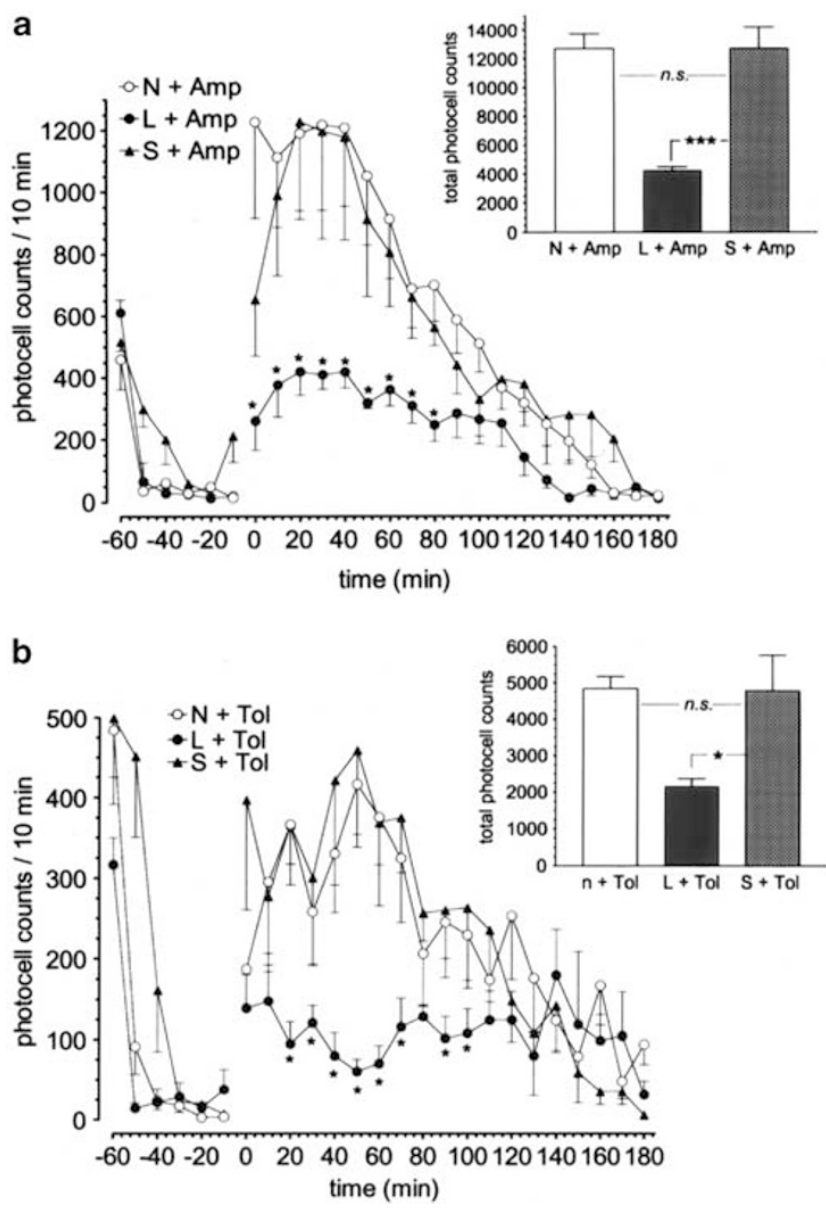

Figure I Acute locomotor stimulant properties of (a) amphetamine (Amp, $1.5 \mathrm{mg} / \mathrm{kg}$, i.p.) and (b) toluene (Tol, $600 \mathrm{mg} / \mathrm{kg}$, i.p.) in naive (N)-, sham (S)-, and 6-OHDA-lesioned (L) animals. Injections were given at time ' $O$ ' following a $60 \mathrm{~min}$ acclimation period. For the time courses, data represent the mean photocell counts \pm SEM at each 10 min interval. Note the different scaling on the $y$-axis of (a) and (b). Significant differences between treatment groups were determined by a repeated measure analysis of variance followed by post hoc testing using Dunnett's multiple comparison test. In both Tol and Amp treatments significant differences were found between the $(\mathrm{L})$ and $(S)$ groups, ${ }^{*} P<0.0$ I (Student's t-test) Inset graphs depict the mean total photocell counts over the entire $3 \mathrm{~h}$ recording period following $\mathrm{Amp}$ and Tol. $* * * P<0.001, * P<0.05$, NS - nonsignificant (Student's t-test)

animals to the test drugs were indistinguishable from each other $(P=0.92)$ (Figures 1 and 2$)$. An examination of the time courses of drug action also revealed that amphetamine- and toluene-induced activity peaked between 20 $60 \mathrm{~min}$ postinjection. In contrast to the stimulatory effects of toluene and amphetamine, the magnitude and time course of the stimulatory effects evoked by either scopolamine or vehicle were not altered by 6-OHDA lesions $(P>0.05$ when compared to sham controls) (Figure $2 \mathrm{a}, \mathrm{b}$ ), a result consistent with previously published reports (Joyce and Koob, 1981; French and Vantini, 1984). All treatment groups demonstrated adequate habituation to the test cages as evidenced by the rapid decline in activity during the $1 \mathrm{~h}$ of acclimation prior to drug treatment.

The subsequent neurochemical analysis (Figure 3 ) of the NAC found DA levels to be significantly reduced ( $~ 90 \%$; $P<0.001$, Student's $t$-test) in the 6-OHDA-treated animals. 

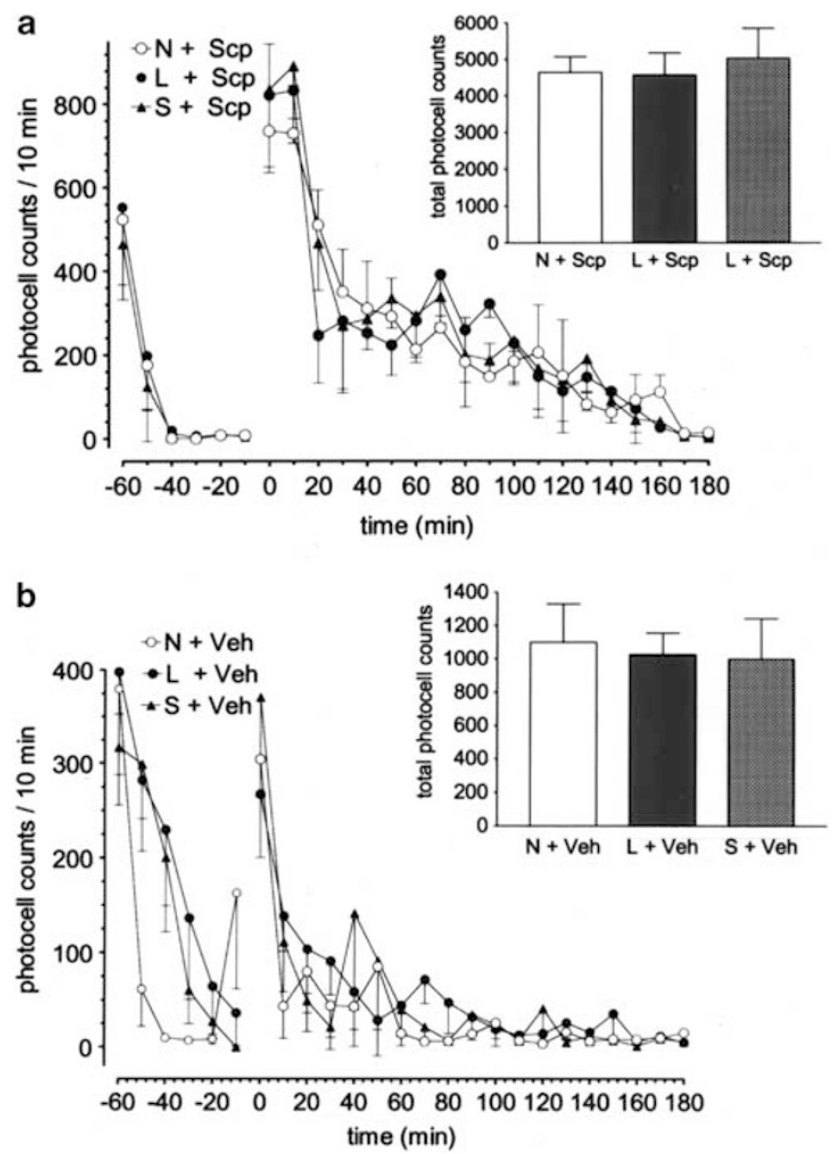

Figure 2 Effects of scopolamine (a) ( $\mathrm{Scp}, 1.25 \mathrm{mg} / \mathrm{kg}$, i.p.) and vehicle (b) (Veh, $600 \mathrm{mg} / \mathrm{kg}$, i.p.) on locomotor activity in naive (N)-, sham (S)-, and 6OHDA-lesioned (L) animals. Data represent the mean photocell counts \pm SEM at each 10 min interval. Injections were given at time ' $O$ ' following a $60 \mathrm{~min}$ acclimation period. Note the different scaling on the $y$ axis of (a) and (b). Inset graphs depict the mean total photocell counts over the $3 \mathrm{~h}$ recording period following scopolamine or vehicle for each group. Differences between groups were nonsignificant ( $P>0.05$, Student's t-test).

In contrast, DA concentrations in the naive group $(884 \pm 24 \mathrm{ng} / 100 \mathrm{mg}$ wet weight) and sham-lesion group $(873 \pm 44 \mathrm{ng} / 100 \mathrm{mg})$ were nearly identical $(P>0.05)$ (Figure 3).

\section{LY379268 Experiments}

An extensive body of literature demonstrates that the acute administration of LY379268 is associated with a nonspecific motor-depressant effect, to which animals develop a rapid tolerance with repeated administration (Cartmell et al, 1999, $2000 \mathrm{~b})$. Consistent with these reports, we also found that the initial injections of LY379268 used here produced a reduction in spontaneous activity compared to the vehicle groups receiving water. In order to overcome these motordepressant effects, the animals ( $n=6$ /group) were given repeated daily injections of LY379268 in a manner similar to previously published studies, and then $30 \mathrm{~min}$ later injected (i.p.) again with $1.5 \mathrm{ml}$ (i.p.) olive oil vehicle (Cartmell et al, $1999,2000 \mathrm{a}, \mathrm{b})$. Using this procedure we found that over the course of these daily pretreatments with LY379268 (8-12 days) the locomotor-depressant effects of LY diminished, eventually becoming indistinguishable from activity levels

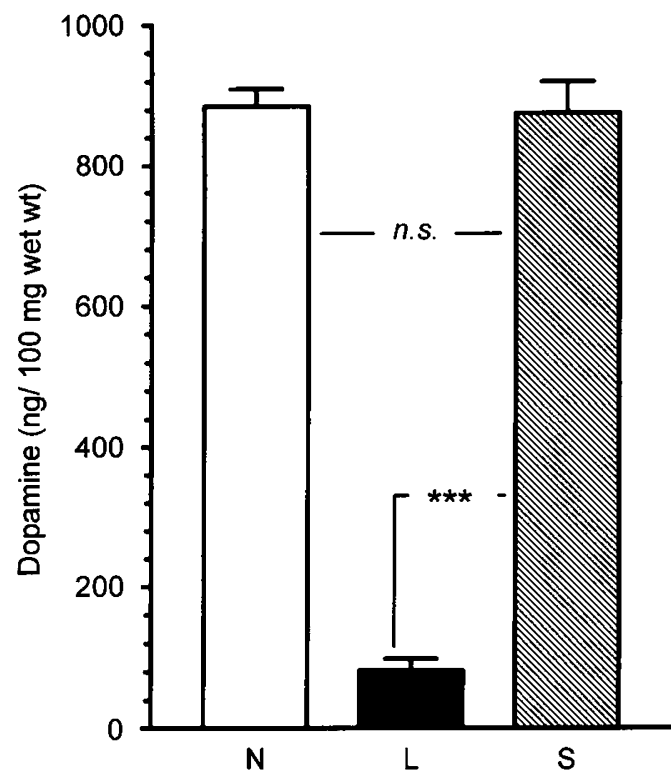

Figure 3 DA levels in the NAC of naive (N)-, sham (S)-, and 6-OHDAlesioned $(\mathrm{L})$ animals. Data represent the mean tissue concentrations (ng/ $100 \mathrm{mg}$ wet weight \pm SEM). Significant differences in DA levels between treatment groups were determined by the Student's $t$-test, $* * * * P<0.00$ I, NS - nonsignificant.

of the animals receiving only daily vehicle pretreatments followed by olive oil $(P>0.05)$. This result concurs with that reported by Cartmell et al (1999, 2000b). Specifically, the number of injections needed to reduce the locomotordepressant effects of LY379268 was directly proportional to the dose administered. That is, for animals receiving 1.5, 3,

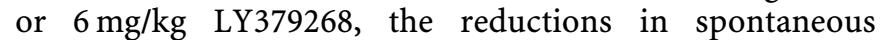
activity were no longer evident by the 8th, 9th, and 12th day of treatment, respectively. With the elimination of the nonspecific motor effects of LY the animals were then challenged with toluene. As seen in Figure 4, tolueneinduced locomotor activity was reduced in the LY-treated animals in a dose-dependent fashion $(P<0.001, \mathrm{~F}=19.1 \mathrm{df}$ $4,25)$. Specifically, the locomotor response to toluene in animals pretreated with $1.5,3.0$, or $6.0 \mathrm{mg} / \mathrm{kg}$ LY379268 was 68.5\% $(P<0.01), 43.6 \%(P<0.001)$, and $29.0 \%(P<0.001)$ of the activity elicited by toluene in animals receiving repeated daily vehicle injections, respectively (Figure 4).

\section{DISCUSSION}

\section{6-OHDA Studies and Toluene}

The present results strongly suggest that the locomotor stimulatory effect of toluene is mediated via a specific site of action rather than by a nonspecific generalized effect throughout the CNS. Moreover, our findings in 6-OHDAlesioned animals indicate that toluene-induced locomotor activity is ultimately dependent upon intact dopaminergic neurotransmission in the NAC. Similar inhibitory effects of 6-OHDA lesions have also been reported for amphetamine, cocaine, and PCP, forming the basis for the conclusion that many drugs of abuse act through a mesolimbic-DA dependent mechanism (Joyce and Koob, 1981; Wise and Bozarth, 1987). In contrast, the locomotor activation 


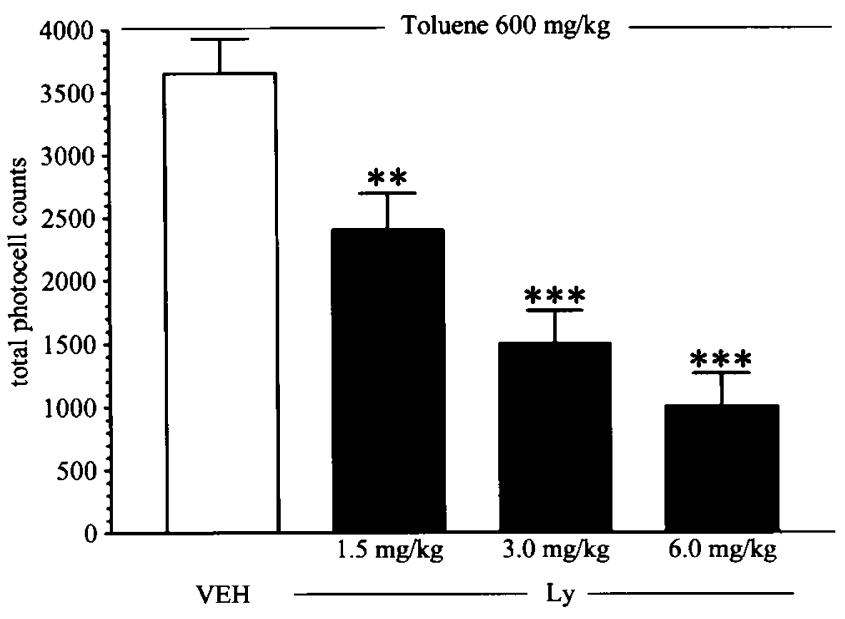

Figure 4 Toluene-induced locomotor activity is reduced in a dosedependent fashion in rats behaviorally tolerant to the motor-depressant effects of LY379268. At $24 \mathrm{~h}$ after the last injection of LY379268 (days 9, I0, and I3), rats received an injection of vehicle (VEH), I.5, 3.0, or $6.0 \mathrm{mg} /$ $\mathrm{kg}$ LY379268 followed $30 \mathrm{~min}$ later by toluene $(600 \mathrm{mg} / \mathrm{kg}$, i.p.). All pretreatment injections were preceded by a $60 \mathrm{~min}$ acclimation period. ** $P<0.01$ and **** $P<0.001$ indicate statistically significant differences between treatment groups and vehicle (Student's t-test).

produced by scopolamine, a muscarinic receptor antagonist, is unaltered by 6-OHDA lesions and considered, therefore, not to be mediated through DA neurotransmission within the NAC (Joyce and Koob, 1981; French and Vantini, 1984). The blockade of 6-OHDA destruction of noradrenergic terminals supports a predominant role of DA in toluene-induced hyperactivity. This dependence on DA neurotransmission for the behavioral stimulatory effect of toluene would also concur with previous reports showing that a selective DA receptor antagonist can block tolueneinduced hyperactivity (Riegel and French, 1999c). Therefore, it would appear that the locomotor activation elicited by toluene, like that of other psychomotor stimulants, is mediated through DAergic mechanisms within the mesolimbic NAC. Notably, it is the activation of this system, which is also thought to play a prominent role in the motivational aspects of drug reward (Koob, 1992; Kalivas, 1993). Nonetheless, the central question of how toluene might increase DA neurotransmission in the NAC remains to be answered. Although explanations are not immediately forthcoming from the present data, there are several speculative mechanisms both inside and outside the NAC which are pertinent. Westerink and Vijverberg (2002) recently demonstrated a toluene-induced increase in the frequency of vesicular catecholamine release from PC12 cells. Intriguingly, this effect was dependent upon calcium influx via voltage-gated calcium channels (VGCC). By analogy, toluene could conceivably activate VGCC in the NAC to release directly DA. Alternatively, the toluene-PC12 cell effect may reflect a membrane depolarization (Westerink and Vijverberg, 2002). This second possibility is interesting given that (1) at present there exists no data supporting a toluene-related impulse-independent, amphetamine-like mechanism of action and (2) in vivo tolueneassociated release of neurotransmitter is reported as TTX sensitive, and thus likely impulse dependent (Stengard and O'Connor, 1994; Westerink and Vijverberg, 2002).
At the behavioral level, volatile inhalants like toluene share considerable overlap with other CNS depressants such as barbiturates, benzodiazepines, and ethanol (EtOH), and so may possess similar mechanisms of action (Hinman, 1987; Bowen et al, 1999). The administration of these substances in rats has been shown to stimulate DA release (DiChiara and Imperato, 1988; Stengard et al, 1994; Yim et al, 1998, 2002). At the systems level, the increased release of DA associated with the administration of toluene and the CNS-depressant EtOH has been temporally associated in vivo with an increase in the number of impulses originating within the VTA, the site of origin of the mesolimbic DA pathway (Gessa et al, 1985; Riegel and French, 1999a, b). At the cellular level both substances stimulate DA neuronal activity - an effect that has been attributed to disinhibitory mechanisms as well as the direct activation of VTA DA neurons (Brodie et al, 1990, 1999). Taken together, these noticeable similarities would appear to support the general conclusions that the abused inhalant toluene may trigger the release of DA in the NAC via impulse-dependent mechanisms initiated upstream at the level of the cell bodies in the VTA.

Given the recognized correlation between drugs of abuse, locomotor hyperactivity and DA release in the NAC, the present results were anticipated. Thus, the data presented here would also be consistent with a number of other observations showing toluene-evoked (1000-2000 ppm) release of DA, GABA, and acetylcholine in motor pathways, cortical structures, and the cerebellum (Stengard et al, 1993; Stengard and O'Connor, 1994). Nonetheless, two microdialysis studies did not find a similar toluene-related (3000 ppm and $800 \mathrm{mg} / \mathrm{kg}$, i.p.) increase of DA in the striatum or NAC, respectively (Kondo et al, 1995; Gerasimov et al, 2002). While these reports may appear contradictory, they may more likely underscore several important conditions underlying the toluene-induced release of DA.

Drugs of abuse that stimulate motor (nigrostriatal) pathways generally also stimulate reward (mesolimbic) pathways, albeit at lower concentrations. Moreover, the reinforcement produced by such psychoactive substances is related to changes in drug concentration in the brain rather than to steady-state blood levels (Balster and Schuster, 1973). Rapid changes in brain concentrations are also reflected as having greater reinforcement efficacy and, in fact, with increasing exposure durations, drug reinforcement responses show a change in response rates similar to a decrease in unit dose (Balster and Schuster, 1973). As the behavioral effects of a drug must ultimately result from some alteration in neuronal activity, it is particularly interesting that abuse-relevant concentrations of toluene in the blood $(\sim 300 \mu \mathrm{M})$ are very efficacious at stimulating VTA DA neuronal activity both in vivo andin vitro: an effect principally observed during transient (seconds to minutes) 'pulses' of the solvent (Riegel and French, 1999a, 2002). As the 'pulse' length is extended beyond $\sim 12-15$ min VTA DA neurons both in vivo and in vitro rapidly inactivate through an apparent depolarization block mechanism (Riegel and French, 1999a, 2002). Thus, the absence of change in striatal or accumbal extracellular DA (Kondo et al, 1995; Gerasimov et al, 2002) could result from a blood/brain concentration of toluene at a level that is actually reducing DA neuronal activity, possibly through a depolarization inactivation 
mechanism. Coincidently single i.p. injections of drugs such as ethanol also produce substantial, albeit transient, increases in DA release. However, accumbal DA concentrations rapidly return to basal levels despite the continued presence of elevated brain concentrations of ethanol (Yim et al, 2000). A similar cell body-terminal relation may explain in part why primates will self-administer single $15 \mathrm{~s}$ 'pulses' of toluene (3000 ppm) (Weiss et al, 1979), but changes in accumbal DA release in rats are not apparent during continuous exposure to the same concentration of solvent (Gerasimov et al, 2002). Such mechanisms may also explain why human abusers do not continuously ( $>15 \mathrm{~min}$ ) inhale for long periods, but rather prefer to titer their doses by repeatedly 'huffing' very-high-exposure concentrations for only seconds to minutes (Flanagan and Ives, 1994).

\section{Experimental Protocol and Blood Toluene Concentrations (BTC)}

Toluene dose-effect relations with inhalation exposure is complex. 'Behaviorally relevant' BTCs can only be described adequately by examining two variables, exposure concentration and duration (Miyagawa et al, 1984). For instance, similar BTCs of $\sim 800 \mu \mathrm{M}$ can be generated by exposure to $11500 \mathrm{ppm}$ for $16 \mathrm{~min}$ or $1780 \mathrm{ppm}$ for $100 \mathrm{~min}$ (Rees et al, 1985; Riegel and French, 1999a). It should be pointed out, however, that inhalation exposure does produce highly variable BTC in animals exposed to the same concentrations over the same period of exposure (Rees et al, 1985). Moreover, toluene vapors are irritating to the eyes at concentrations as low as $100 \mathrm{ppm}$ (Andersen et al, 1983). For these reasons i.p. injections were used in the present study. This route of administration is also routinely used in animals to study drugs commonly abused by humans either by inhalational or oral ingestion (eg cannabinoids, nicotine, cocaine and amphetamines) (Miyagawa et al, 1984). In a study by Wada (1999) where rats were administered the identical $600 \mathrm{mg} / \mathrm{kg}$ i.p. of toluene, as done here, BTC were measured at $\sim 790 \mu \mathrm{M}$, a value consistent with a number of behaviorally relevant reports addressing the rewarding properties of abused inhalants (Table 1).

\section{LY379268 Studies and Toluene}

The present finding that LY379268, a selective mGlu2/3 agonist, attenuated toluene-induced activity further suggests that mGlu receptors (mGluRs) may be recruited subsequent to the toluene-induced increase in DA neurotransmission (Cartmell and Schoepp, 2000; Xi et al, 2002). Typically inactive, mGluRs function as autoreceptors during elevated neuronal activity to attenuate DA, GABA, glutamate, and acetylcholine release (Cartmell and Schoepp, 2000). Given the widespread influence of mGluRs and the list of ion channel and G-protein coupled receptors affected by toluene, further research is necessary to clarify the cellular sequence of events underlying any toluene-induced behavior (Bale et al, 2002; Cruz et al, 1988; Beckstead et al, 2000; Tsuga et al, 1999, 2002). Nevertheless, the above observations at the systems level are consistent with the fact that LY379268 similarly reduces the DA-dependent behavioral effects of PCP and to a lesser extent those of amphetamine (Moghaddam and Adams, 1998; Cartmell et al, 1999, 2000a; Clark et al, 2002). Although it is unclear where in the brain LY379268 may act to block the locomotor stimulatory effects of toluene, the modulation of excitatory glutamatergic afferents from prefrontal cortex (PFC) to

Table I

\begin{tabular}{|c|c|c|}
\hline End point & Blood toluene concentration & \\
\hline \multicolumn{3}{|l|}{ In vivo } \\
\hline Self administration (human) & $\sim 330 \mu M^{a, b}$ & Garriott et al $(1981)^{a}$ \\
\hline Conditioned place preference (mice) & $<220 \mu M^{c, b}$ & Funada et al (2002) \\
\hline Onset CNS excitation & $294 \mu M^{a}$ & Kishi et al $(1988)^{a}$ \\
\hline$\uparrow$ Locomotor activity, no ataxia & $<792 \mu \mathrm{M}^{\mathrm{c}, \mathrm{b}}$ & Riegel and French (1999c) \\
\hline$\uparrow$ Locomotor activity $+\uparrow$ ataxia & $>800 \mu M^{c, b}$ & Kondo et al (1995) \\
\hline$\uparrow \mathrm{DA}$ (microdialysis striatum) & $349 \mu M^{c, b}$ & Stengard et al (1994) \\
\hline \multirow[t]{3}{*}{$\rightarrow \mathrm{DA}$ (micro dialysis NAC) } & $>800 \mu M^{c, b}$ & Kondo et al (1995) \\
\hline & $700-1090 \mu \mathrm{M}$ at $20-120 \mathrm{~min}^{\mathrm{c}, \mathrm{b}}$ & Gerasimov et al (2002) \\
\hline & $700-1090 \mu \mathrm{M}$ at $20-120 \mathrm{~min}^{\mathrm{c}, \mathrm{b}}$ & Gerasimov et al (2002) \\
\hline$\uparrow D A$ (micro dialysis PFC) & & \\
\hline \multicolumn{3}{|l|}{ In vitro } \\
\hline \multirow{7}{*}{\multicolumn{3}{|c|}{ 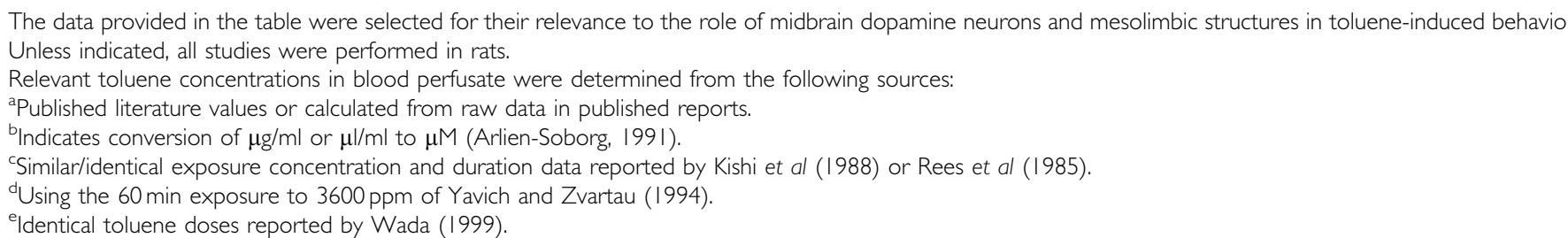 }} \\
\hline & & \\
\hline & & \\
\hline & & \\
\hline & & \\
\hline & & \\
\hline & & \\
\hline \multicolumn{3}{|c|}{$\uparrow, \downarrow, \neg$ refers to increases, decreases, and no change respectively; DpB refers to depolarization block. } \\
\hline
\end{tabular}


VTA DA neurons should be examined (Wang and French, 1993; Karreman et al, 1996). Another possibility includes an LY379268-NAC interaction, which could in a sense pharmacologically replicate our chemical lesions induced by 6-OHDA. Interestingly, $\mathrm{Hu}$ et al (1999) reported that direct injections of the group II mGluR agonist DCG-4 into the NAC reduced extracellular levels of DA in that structure. Moreover, the application of the nonselective mGluR agonist $t$-ACPD directly into the NAC blocked PFC- or VTA-electrical stimulation-induced increases in NAC DA (Taber and Fibiger, 1995). Also, the superfusion of selective mGluR3 agonists such as L-AP4 onto accumbal slices is reported to inhibit DA release (Manzoni et al, 1997). While an LY379268-PFC mechanism cannot be ruled out, it appears unlikely. Data from a related report indicates that the neurochemical changes produced in the PFC following systemic injections of LY379268 could not be mimicked when LY379268 was applied locally (Cartmell et al, 2001). Thus, multiple lines of evidence support the toluene-related stimulation of DA neurotransmission in the NAC.

In summary, these experiments provide the first data associating the locomotor-stimulant effects of toluene with increased DA release specific to the mesolimbic NAC. This finding provides an important indication that inhalants may target the same neuronal substrate activated by most drugs of abuse. This connection may be particularly important for a better understanding of the abuse potential of inhalants containing toluene and the identification of the functional consequences of toluene abuse. These results are also consistent with the effects of other commonly abused drugs, which consistently show a striking specificity for primary mesolimbic DA reward fibers. Moreover, the attenuation of toluene's locomotor effects by a selective mGluR2/3 agonist may provide insight into the development of novel therapeutic interventions for the treatment of inhalant addiction.

\section{ACKNOWLEDGEMENTS}

Arthur Riegel was supported by Grant \# NIDA T-334180.

\section{REFERENCES}

Andersen I, Lundqvist GR, Molhave L, Pedersen OF, Proctor DF, Vaeth M, Wyon DP (1983). Human response to controlled levels of toluene in six-hour exposures. Scand J Work Environ Health 9: 405-418.

Arlien Soborg P (1991). Solvent Neurotoxicity: Toluene. CRC Press: Boca Raton, FL. 382pp.

Bale AS, Smothers CT, Woodward JJ (2002). Inhibition of neuronal nicotinic acetylcholine receptors by the abused solvent, toluene. Br J Pharmacol 137: 375-383.

Balster RL (1998). Neural basis of inhalant abuse. Drug Alcohol Depend 51: 207-214.

Balster RL, Schuster CR (1973). Fixed-interval schedule of cocaine reinforcement: effect of dose and infusion duration. J Exp Anal Behav 20: 119-129.

Beckstead MJ, Weiner JL, Eger II EI, Gong DH, Mihic SJ (2000).

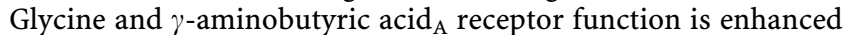
by inhaled drugs of abuse. Mol Pharmacol 57: 1199-1205.

Bowen SE, Wiley JL, Jones HE, Balster RL (1999). Phencyclidineand diazepam-like discriminative stimulus effects of inhalants in mice. Exp Clin Psychopharmacol 7: 28-37.
Brodie MS, Pesold C, Appel SB (1999). Ethanol directly excites dopaminergic ventral tegmental area reward neurons. Alcoholism: Clin Exp Res 23: 1848-1852.

Brodie MS, Shefner SA, Dunwiddie TV (1990). Ethanol increases the firing rate of dopamine neurons of the rat ventral tegmental area in vitro. Brain Res 508: 65-69.

Cartmell J, Monn JA, Schoepp DD (1999). The metabotropic glutamate $2 / 3$ receptor agonists Ly354740 and LY379268 selectively attenuate phencyclidine versus D-amphetamine motor behaviors in rats. J Pharmacol Exp Ther 291: 161-170.

Cartmell J, Monn JA, Schoepp DD (2000a). The mGlu2/3 receptor agonist LY379268 selectively blocks amphetamine ambulations and rearing. Eur J Pharmacol 400: 221-224.

Cartmell J, Monn JA, Schoepp DD (2000b). Tolerance to the motor impairment, but not to the reversal of PCP-induced motor activities by oral administration of the $\mathrm{mGlu} 2 / 3$ receptor agonist, LY379268. Nauyn Schmiedebergs Arch Pharmacol 361: 39-46.

Cartmell J, Perry KW, Salhoff CR, Monn JA, Schoepp DD (2001). Acute increases in monoamine release in the rat prefrontal cortex by the mGlu2/3 agonist LY379268 are similar in profile to risperidone, not locally mediated, and can be elicited in the presence of uptake blockade. Neuropharmacology 40: 847-855.

Cartmell J, Schoepp DD (2000). Regulation of neurotransmitter release by metabotropic glutamate receptors. J Neurochem 75: 889-907.

Clark M, Johnson B, Wright R, Monn J, Schoepp D (2002). Effects of the mGlu2/3 receptor agonist LY379268 on motor activity in phencyclidine-sensitized rats. Pharmacol Biochem Behav 73: 339-346.

Cruz SL, Mirshani T, Thomas B, Balster RL, Woodward JJ (1988). Effects of the abused solvent toluene on recombinant $N$-methyl-D-aspartate and non- $N$-methyl-D-aspartate receptors expressed in Xenopus oocytes. J Pharmacol Exp Ther 286: 334-340.

DiChiara G, Imperato A (1988). Drugs abused by humans preferentially increase synaptic dopamine concentrations in the mesolimbic system of freely moving rats. Proc Natl Acad Sci USA 85: 5274-5278.

Flanagan RJ, Ives RJ (1994). Volatile substance abuse. Bull Narc 46 : 49-78.

Frazer A (2001). Serotonergic and noradrenergic reuptake inhibitors: predicition of clinical effects from in vitro potencies. J Clin Psychiatry 62(Suppl): 16-23.

French ED, Riegel A (2001). The excitatory effects of the abused inhalant toluene in rat VTA neurons in vitro appears not to be mediated by NMDA receptor activation. 31st Annual Meeting of the Society for Neuroscience, abstract \#6312.

French E, Vantini G (1984). Phencyclidine-induced locomotor activity in the rat is blocked by 6-hydroxydopamine lesion of the nucleus accumbens: Comparisons to other psychomotor stimulants. Psychopharmacology 82: 83-88.

Funada M, Sato M, Makino Y, Wada K (2002). Evaluation of the rewarding effect of toluene by conditioned place procedure in mice. Brain Res Protocols 10: 47-54.

Garriott J, Foerster E, Juarez L (1981). Measurement of toluene in blood and breath in cases of solvent abuse. Clin Toxicol 18: 471-479. Gerasimov MR, Schiffer WK, Marstellar D, Ferrieri R, Alexoff D, Dewey SL (2002). Toluene inhalation produces regionally specific changes in extracellular dopamine. Drug Alcohol Depend 65: 243-251.

Gessa G, Muntoni F, Collu M, Vargiu L, Mereu G (1985). Low doses of ethanol activate dopaminergic neurons in the ventral tegmental area. Brain Res 348: 201-203.

Hinman DJ (1987). Biphasic dose-response relationship for effects of toluene inhalation on locomotor activity. Pharmacol Biochem Behav 26: 65-69. 
Hu G, Duffy P, Swanson C, Ghasemzadeh MB, Kalivas PW (1999). The regulation of dopamine transmission by metabotropic glutamate receptors. J Pharmacol Exp Ther 289: 412-416.

Imam SZ, Ali SF (2001). Aging increases the susceptiblity to methamphetamine-induced dopaminergic neurotoxicity in rats: correlation with peroxynitrite production and hyperthermia. $J$ Neurochem 78: 952-959.

Joyce EM, Koob GF (1981). Amphetamine-, scopolamine- and caffeine-induced locomotor activity following 6-hydroxydopamine lesions of the mesolimbic dopamine system. Psychopharmacology 73: 311-313.

Kalivas PW (1993). Neurotransmitter regulation of dopamine neurons in the ventral tegmental area. Brain Res Rev 18: 75-113.

Karreman M, Westerink BHC, Moghaddam B (1996). Excitatory amino acid receptors in the ventral tegmental area regulate dopamine release in the ventral striatum. J Neurochem 67: 601-607.

Kondo H, Huang J, Ichihara G, Kamijima I, Saito E, Shibata Y, Ono N, Hisanaga Y, Takeuchi Y, Nakahara D (1995). Toluene induces behavioral activation without affecting striatal dopamine metabolism in the rat: behavioral and microdialysis studies. Pharmacol Biochem Behav 51: 97-101.

Kono J, Miyata H, Ushijima S, Yanagita T, Miyasato K, Ikawa G, Hukui K (2001). Nicotine, alcohol, methamphetamine, and inhalant dependence: a comparison of clinical features with the use of a new clinical evaluation form. Alcohol 24: 99-106.

Koob GF (1992). Drugs of abuse: anatomy, pharmacology, and function of reward pathways. Trends Pharmacol Sci 13: 177-184.

Manzoni O, Michel JM, Bockaert J (1997). Metabotropic glutamate receptors in the rat nucleus accumbens. Eur J Neurosci 9: 15141523.

Miyagawa M, Honma T, Sato M, Hasegawa H (1984). Effects of single exposure to toluene on operant behavior and brain toluene levels in rats. Ind Health 22: 127-131.

Moghaddam B, Adams BW (1998). Reversal of phencyclidine effects by a group II metabotropic glutamate receptor agonist in rats. Science 281: 1349-1352.

National Institute on Drug Abuse, National Survey Results on Drug Use from the Monitoring the Future Study (1999).

Ohishi H, Ogawa-Meguro R, Shigemoto R, Kaneko T, Nakanishi S, Mizuno N (1994). Imuunohistochemical localization of metabotropic glutamate receptors, mGluR2 and mGluR3, in rat cerebellar cortex. Neuron 13: 55-66.

Rees DC, Wood RW, McCormick BA, Cox C (1985). Toxicokinetics of toluene in the rat. Scand J Work Environ Health 11: 301-306.

Riegel AC, French ED (1999a). An electrophysiological analysis of rat ventral tegmental dopamine neuronal activity during acute toluene exposure. Pharmacol Toxicol 85: 37-43.

Riegel AC, French ED (1999b). The susceptibility of rat nondopamine ventral tegmental neurons to inhibition during toluene exposure. Pharmacol Toxicol 85: 44-46.

Riegel AC, French ED (1999c). Acute toluene induces biphasic changes in rat spontaneous locomotor activity which are blocked by remoxipride. Pharmacol Biochem Behav 62: 399-402.

Riegel AC, French ED (2002). Abused inhalants and central reward pathways. Electrophysiological and behavioral studies in the rat. Ann NY Acad Sci 965: 281-291.

Schoepp DD (2001). Unveiling the functions of presynaptic metabotropic glutamate receptors in the central nervous system. J Pharmacol Exp Ther 299: 12-20.

Shigemoto R, Kinoshita A, Wada E, Nimura S, Ohishi H, Takada M, Flor PJ, Neki A, Abe T, Nakanishi S, Mizuno N (1997). Differential presynaptic localization of metabtoropic glutamate receptor subtypes in rat hippocampus. J Neurosci 17: 7503-7522.
Stengard K (1994). Effect of toluene inhibition on extracellular striatal acetylcholine release studied with microdialysis. Pharmacol Toxicol 75: 115-118.

Stengard K, Hoglund G, Ungerstedt U (1994). Extracellular dopamine levels within the striatum increase during inhalation exposure to toluene: a microdialysis study in awake, freely moving rats. Toxicol Lett 71: 245-255.

Stengard K, O'Connor WT (1994). Acute toluene exposure decreases extracellular ã-aminobutyric acid in the globus pallidus but not in striatum: a microdialysis study in awake, freely moving rats. Eur J Pharmacol 292: 43-46.

Stengard K, Tham R, O'Connor WT, Hoglund G, Ungerstedt U (1993). Acute toluene increases extracellular GABA in the cerebellum of rat: a microdialysis study. Pharmacol Toxicol 73: $315-318$

Taber MT, Fibiger HC (1995). Electrical stimulation of the prefrontal cortex increases dopamine release in the nucleus accumbens of the rat: modulation by metabotropic glutamate receptors. J Neurosci 15: 3896-3904.

Testa CM, Standaert DG, Young AB, Penney Jr JB (1994). Metabotropic glutamate receptor mRNA expression in the basal ganglia of the rat. J Neurosci 14: 3005-3018.

Tsuga H, Haga T, Honma T (2002). Effects of toluene exposure on signal transduction: toluene reduced the signaling via stimulation of human muscarinic acetylcholine receptor $\mathrm{m} 2$ subtypes in CHO cells. Jpn J Pharmacol 89: 282-289.

Tsuga H, Wang RS, Honma T (1999). Effects of toluene on regulation of adenylyl cyclase by stimulation of G-proteincoupled receptors expressed in CHO cells. Jpn J Pharmacol 81: 305-308.

von Euler G (1994). Toluene and dopaminergic transmission. In: Isacsson R, Jensen K (eds) The Vulnerable Brain and Environmental Risks, Toxins in Air and Water, Vol. 3 Plenum Press, New York. pp 301-321.

Wada H (1999). Toluene and temporal discrimination in rats: effects on accuracy, discriminability, and time estimation. Neurotoxicol Teratol 21: 709-718.

Wang T, French ED (1993). L-glutamate excitation of A10 dopamine neurons is preferentially mediated by activation of NMDA receptors: extra- and intracellular electrophysiological studies in brain slices. Brain Res 627: 299-306.

Weiss B, Wood RW, Macys DA (1979). Behavioral toxicology of carbon disulfide and toluene. Environ Health Perspect 30: 39-45.

Westerink RHS, Vijverberg HPM (2002). Toluene-induced, $\mathrm{Ca}^{2+}$ dependent vesicular catecholamine release in rat PC12 cells. Neurosci Lett 326: 81-84.

Wise R, Bozarth M (1987). A psychomotor stimulant theory of addiction. Psychol Rev 94: 469-492.

Xi Z-X, Baker DA, Shen H, Carson DS, Kalivas PW (2002). Group II metabotropic glutamate receptors modulate extracellular glutamate in the nucleus accumbens. J Pharmacol Exp Ther 300: 162171.

Yavich L, Zvartau E (1994). A comparison of the effects of individual organic solvents and their mixture on brain stimulation reward. Pharmacol Biochem Behav 48: 661-664.

Yim HJ, Robinson DL, White ML, Jaworski JN, Randall PK, Lancaster FE, Gonzales RA (2000). Dissociation between the time course of ethanol and extracellular dopamine concentrations in the nucleus accumbens after a single intraperitoneal injection. Alcoholism: Clin Exp Res 24: 781-788.

Yim HJ, Schallert T, Randall PK, Gonzales RA (1998). Comparison of local and systemic ethanol effects on extracellular dopamine concentration in rat nucleus accumbens by microdialysis. Alcoholism: Clin Exp Res 22: 367-374. 